\title{
Literary Translation from a Stylistic Perspective
}

\author{
Hasan Said Ghazala ${ }^{1 *}$ \\ 1 Department of English, College of Social Sciences, Umm Al-Qura university, Makkah \\ Al-Mukarramah, Saudi Arabia \\ *Hasan Said Ghazala, E-mail: Ghazala@uqu.edu.sa
}

\begin{abstract}
This paper is intended to lay some grounds for aspects of literary translation both in theory and in practice. It provides definitions for basic terms and concepts of the major topics and issues pertaining to literary translation. Among the terms and concepts essential to the readers/students' background knowledge in this connection are: Literature, literary language vs. non-literary language; the literariness of literature, literary translation vs. non-literary translation, the literary translator and methods of literary translation. The paper ends with setting forth a creative literary stylistic method of translating literature. These points are scrupulously elaborated and updated to reflect the latest in the field.

The ultimate objective of this paper is to provide a view of a number of means and requirements of a good literary translation today, and finally set forth a relatively creative approach to literary translation based on a literary stylistic method.
\end{abstract}

\section{Keywords}

literary translation, literature, literariness, stylistic, literary translator, translation method, creativity, literary

\section{Introduction: Defining Literature}

To many, it is a waste of time to define literature, for everybody knows what literature is. Obviously, it is prose (novels and short stories), poetry and drama. Nobody mistakes them for something else. Well, specialists, as usual, may find the defining process of literature as more complicated than just defining it in terms of its main genres (whose parameters are not self-evident at least to some). Various attempts have been made to define literature by writers and men/women of letters themselves.

Going as far back as to Aristotle (in his famous work, Poetics) and Plato (and his widely known book, The Republic), the latter defined literature by making a distinction between two modes of speech representation, diegesis, or "pure narrative" (the discourse of the narrator/poet) and mimesis (the directly imitated or enacted speech of the characters themselves, as in dramatic dialogue). The former, however, took literature to be mainly mimesis, which means that literature was mainly mimetic in its aim to present "the illusion of a representation of the real world". In other words, literature can be described as an illusory reflection of real life, where words replace actions (see Wales, 1989, p. 300). 
Not far from that is the popular definition of literature in terms of imaginative writing, i.e., fiction which stands in contrast to fact. That is, unlike non-literary real texts, literature is about untrue events and people. Well, how about true stories? Are Superman comic and cartoons literature? Other definitions of literature were in terms of creativity, subject matter, symbolism, figurativeness, transcendentalism, essence, aesthetics and estranged and peculiar language that is deviant from ordinary language of daily use (see Eagleton, 1983, ch. 1; Wales, 1989, p. 279; Wellek, 1982, ch. 1; Williams, 1976/1983; Ghazala, 2012, ch. 1, and others).

One or two further definitions of literature were based on conventionality, that is, a work is "recognized as a work of literature by generation after generation", as Cohen claims. This definition is based neither on linguistic, semantic nor literary criteria, but on the criterion of traditions and conventions of recognizing what is literature and what is not. In fact, this is not a reliable criterion for it involves taste and changeability. Generations have a change of perspective and a difference in taste. Therefore, some generations might approve some works as literature, but other generations might not (see Schogt, 1988, pp. 82-83).

Other more recent, articulate and revolutionary definitions of literature include Fowler's who views it "as discourse, and thus, as communication rather than as object", that is, to treat it as mediating relationships between language-users of speech, consciousness, ideology, social role and class. The literary text ceases to be an object and becomes "an action or process" (1981, p. 80). These days, many contemporary writers talk about literary discourse, rather than literary text, or literature, to imply a sense of interaction and communication inculcated in literature (see, for example, Brumfit \& Carter, 1986; Carter \& Simpson, 1989; Simpson, 2004, and many others).

By now, we have come closer to contemporary articulation of the definition of the concept of literature in terms of language more than anything else. Hence the next point.

\section{Literary Language vs. Non-literary Language: Polarization}

There is almost a consensus nowadays on taking up the language of literature as a major, and to some, sole criterion for defining literature and distinguishing between what is literature and what is not.

Literary language has been assigned a special character since antiquity. It has been considered as sublime to, and distinctive from all other types of language, written or spoken, due to the special use of language that is deviant, or "estranged" from ordinary, everyday, non-literary language. It breaks the common norms of language, including graphological, stylistic, grammatical, lexical, semantic and phonological norms.

The Formalists were the pioneers who examined the idea of deviance. They equated literary language with deviation, and claimed that it is used in a particular way and set off in contrast with the normal use of language. But they did not elaborate what the norm of language use could precisely be. Different terms were used by them to define deviation such as "estranging of language", "foregrounding", “defamiliaization", and "automatization" vs. "de-automatization” of ordinary Language (see Carter, 1979, 
Intro.; Ghazala, 1987, 2011; Wales, 1989/2001; Simpson, 2004). Among the obvious shortcomings of the formalists' perspective of literary language was that they identified it with poetry to the neglect of other types like prose and drama.

The American New Critics followed the formalists suit and viewed literary language as a special kind of language use. Some modern stylisticians have viewed it in a way similar to the formalists. Yet, this does not mean that they have defined literary language in terms of deviation only. In fact, they have refuted that and argued with many other contemporary stylisticians and critics that it is not wise to draw a line between literary language and other types of language, and that the ordinary language has been used in literary texts and produced no less stylistic effects than the deviant language. Deviation to them is only one aspect of literary language. (Among those writers are Leech, 1969; Widdowson, 1975; Enkvist, 1973; Chapman, 1973, and others).

Broadly speaking, this argument is true, especially of the language of poetry. However, in reality, it might not be quite applicable. Linguistic/stylistic deviation is required and fairly common in all literary genres for aesthetic, rhetorical and stylo-semantic reasons, whereas they are completely absent, or, at best, occasional in non-literary texts.

Non-literary language is a term which is always considered in conjunction, and in contrast with literary language. Controversy has been and is still going on in academic circles as to the validity of dividing language into these two different types. Traditionally, there has been such division between literature (especially poetry and fictional prose) and non-literature (other types of writing other than what is labeled as literature). The main line of argument is that literary language is emotional, rhetorical, rhythmical, deviant, aesthetic, expressive, symbolic, fictional and, therefore, sublime and superior to non-literary language which is normal, expected, direct, and lacks all other literary characteristics, and, hence, inferior to literary language.

Recently, however, and in the past few years in particular, this view has been challenged by several writers. They claim that such polarization between literary and non-literary language does not exist because they overlap in many texts, and we can find literary features in non-literary texts, and non-literary features in literary texts. (See Fish, 1980; Carter \& Nash, 1983; Widdowson, 1975; Leech $\&$ Short, 1981; Simpson, 2004; Boase-Beier, 2006; Jeffries et al., 2010, to name some).

In fact, there is a point of truth in each of these two points of view. That is, the traditional one is right in its distinction between literature and non-literature, simply because it exists, whether we like it or not. Further, it has a strong linguistic and stylistic basis. The recent one, on the other hand, is true in rejecting the superiority of literature, for a certain social or linguistic context requires-not to say imposes - a certain type of language. For example, nobody is expected to talk or write to a doctor in verse, nor does anybody read a car leaflet or a list of instructions as to how to make a telephone call as a short story full of symbolism, rhetoric, irony and hyperbole. In the same way, no one can mistake a poem for a medical prescription, nor a novel for a telephone directory.

The Formalists' argument about the "speciality" of literary language (i.e. poetry to them), leans heavily 
on the special linguistic/stylistic features (or "devices") of literary language, especially poetry, pointed out above. In other words, linguistic features of the form of a text are the decisive criterion to distinguish between literary and non-literary. On the other hand, The recent linguists and stylisticians who oppose polarization between literary and non-literary language rely in their argument on the recurrence of non-literary features of language in literature, and the coincidence of literary features in non-literature.

Well, I would argue that both views fail to strike a balance between theory and practice. I mean to say that the speciality of literary language is unquestionable, yet, the linguistic features of the form, or the outer shape of the text are sometimes insufficient and might be illusive. By the same token, although features of literary language can recur in non-literary texts (like commercials, or political rhetoric), they do not change these texts into literature; nor these features are used for the same purpose, implication and function in literature. Here are illustrative examples:

The formal features and shape of a text are not good enough to describe a text as literary, as also Schogt declares, “... rhyme and rhythm do not make a literary work...” (1988, p. 82). Here are four examples to support this argument:

(1)

\section{A Joke}

A gentleman dining at Crewe

Found quite a large mouse in his stew;

Said the waiter, Don't shout

And wave it about,

Or the rest will be wanting one, too! (In Nash, 1985, p. 52. See Ghazala, 2008/2012, p. 300)

Although the sense of humor and irony produced by the joke, rhyme and rhythm are prominent features of literary language, they are not good reasons to describe it as literature, for it cannot be taken seriously. Further, our interest and reaction would die down at the punch line of the joke; no more effects, repercussions or symbolic implications are expected. The joke serves a means to an end, i.e., to bring a smile to the audience.

(2)

As long as there's a family without a home,

As long as there is a patient waiting for a hospital bed,

As long as there's a man or woman without a job

Or someone who suffers discrimination because of their color

So long will our work as a Labor government not be done.

We go forward in that spirit and that resolve.

This is a part of political rhetoric by Mr. James Callaghan, the leader of the British Labor Party, during the 1987 general election campaign (in Carter and Nash, 1990, p. 143). The outer shape of the speech, the rhythm, syntactic parallelisms and rhetorical repetitions are features of literary style, yet it cannot 
be considered as a literary text for it cannot be read at more than one level. On the other hand, this type of style is meant to be put in the service of the speaker's election campaign. That is the only level of reading this text, no more no less.

That said, election campaigns and other political topics and issues can be the subject matter of a literary text, as illustrated in the following example (see also Ghazala, 2012a on Translating the Media and Political Idiom):

(3)

\section{On Irish Members of Parliament}

Let them, when they once get in,

Sell the nation for a pin;

While they sit picking straws,

Let them rave at making laws,

While they never hold their tongue,

Let them form a grand committee,

How to plague and starve the city;

(Jonathan Swift, from The Legion Club. In Baker, 1980)

Obviously, the poetic nature of these lines is not questioned owing not only to the prosodic features of rhyme, rhythm and meter, but also to the well-elaboration of words and meanings, semantic density, symbolism, irony, and reading at more than one level (e.g. at the levels of politics, social values, sarcasm, attitudes, corruption, deception, hypocrisy, misery, humanity, criticism, reform, freedom of expression, surveillance of politicians and universality of values, to name some).

(4)

"Through the hollow, on the height, by the heath, by the orchard, by the park, by the garden, over the canal, across the river, where the sheep are feeding, where the mill is going, where the barge is floating, where the dead are lying, where the factory is smoking, where the stream is running. ..." (Charles Dickens, Dumpey and Son)

No doubt, this text is at the heart of literature due to the highly dense and elaborate stylistic-syntactic, stylistic-phonological and stylistic-semantic literary aspects of its language. The passage is perfectly rhythmical, based on isochronism (or equal duration) in the sense of regular periodic beats. In this example, Dickens suggests a kind of regularity of movement which matches the sound of a speeding train. Each phrase is a rhythmical beat which represents phonetically a phase in the train journey, up and down, through and across, by and over different places and landscape scenery, with one exceptional phase of modern, material life (cf. the factory is smoking). These phases are conceptual pauses of imagination that take the speaker as well as readers away from the dim realities of their everyday life.

A concluding remark to these examples and the argument between the pros and cons of "the special language" of literature is that both views are equally defective in their extreme positions: the absolute 
division between literature and non-literature of the first, and the categorical rejection of this division of the second. A compromise is adopted in this book. There is a clear polarity between literary and non-literary language on two conditions: (1) it is not absolute; (2) it should not be considered in terms of superiority and inferiority, just like the division between speech and writing.

After all, and as the discussion of the previous examples indicates, the distinction between literary and non-literary is a distinction between literary and non-literary elements in language. Therefore, the linguistic and stylistic search is for what is literary in literary texts and what is non-literary in non-literary texts. In other words, the search is for the elements of "literariness" and non-literariness in texts. Hence the following point.

\section{What Makes Literature into Literature: Features of Literariness}

The key question now, as also Schogt declares, is "what features make a text literary?" (1988, p. 82). That is a question about what makes literature into literature, what Nash and Carter call "Literariness" (1983). In a paper entitled "Language and Literariness", they carry out a practical survey, aiming at providing a clear vision and definition for the concept of literariness in language. It is done in the form of a comparison between literary and non-literary texts connected by the theme of the motor car. They extend their argument in a later work (1990, ch. 2) and apply the same line of argument to four texts, literary and non-literary, on the topic of Malaysia. They deny to language any imminent literary status as there is no "... single property intrinsic to language which can be called literary". Yet, they do not dismiss the recurrence of properties of literariness in literary texts such as the plotting and elaboration of vocabulary; the imposition of a new thesaurus entry by blending or realigning registers; making moral judgments and discriminations; the possibility of reading at more than one level; polysemy; subtlety of procedure such as irony, and others. Throughout, they have come out with this style-based definition of literariness:

"Literariness in language...comes from the simultaneous operation and interrelation of effects at different levels of language system". It is not "... a function of particular items or processes in lexicon and syntax. It is a property of texts and contexts".

The following conclusions can be drawn from the previous account of Carter and Nash's argument in both of their works (see ibid.):

(1) There are elements of literariness in literary texts that can be identified.

(2) The recognition of these elements is not a straightforward process, but it is implicit in the stylistic patterning of language, the effects produced and their interaction in texts.

(3) The language of literary texts is multi-layered and, thus, the identification of literary properties should be sought for at its different levels, and not at one or two levels only.

(4) Literariness is not an intrinsic property of a lexical item, a stylistic device, a special linguistic feature, but the product of the overlap of the different levels of the language of texts and the effects of that overlap. 
(5) Finally, the so-called properties of literariness are not present in literary texts only; other types of text can display few of them, however very occasionally, and not with such a degree of intensity and richness as in literary texts, and for different purposes. These properties are the point of departure between the literary and the non-literary, and the criteria in terms of which literary texts can be defined properly.

In continuation of the development of the list, I suggest further criteria which are also essential to the identification and definition of the notion of literariness in literature in particular:

(a) The possibility of reading literature at more than one level: the multilayeredness of literature: this means a literary text does not deliver a denotative message, but a connotative message that lies beyond it. This is similar to the criterion of polysemy above, and emphasizes yet more strongly the possibility of multiple and multilayered reading and interpretation of literature any time anywhere in terms of variable and different criteria of social, political, cultural and ideological conventions and backgrounds. Or else, the text cannot be described as really literary. (See also Carter \& Nash, 1990 for further discussion).

(b) Symbolism: a genuine literary work of art is symbolic, representing a real word behind it imaginative world. It is supposed to stand for another thing in human life, what Weinreich terms "enhanced semanticity", or "hypersemanticization", i.e. independent symbolic values of a literary text (in Schogt, 1988, pp. 66-67).

(c) The involvement of human feelings, sentiments and emotions: any literary text inevitably involves human feelings and emotive reactions, which is essential to the readers' actions, reactions and interpretations. It is called by Anani (1997) and Landers (2001) "tone" (see below). This can be decisive especially for a literary translator who is supposed to get engaged with the feelings and sentiments instigated by the SL Text to be able to enliven its world more emotionally than mentally. This will be an essential factor in his construction of literary translation in the Target Language, or he/she may run the risk of failure to do that.

It is hoped now that Schogt's question of what makes literature into literature is now answered, and not as he said twenty four years ago that the question "remains unanswered" (1988, p. 84). In sum, the foregoing argument about literature, literary language and literariness has led to these criteria, with the ultimate objective of putting them to use in practice at translating literature. These criteria are in other words what the literary translator would take as his/her prime target at constructing meaning in the TL. (More on this and other details relative to the literary translator and literary translation is due now).

\section{Translation and Literary Translation}

Rojo's statement that "Translators usually dream of achieving an ideal replica of the ST, but in practice they often have to accept that not everything can be translated exactly into different language" is good to start with $(2009$, p. 22$)$. Indeed, translators, literary or other, do their best to produce an identical version of the SLT in the TL, or a version in the TL as close as possible to the original. Yet, it goes without saying that it is not possible to do it in practice, only relatively if we mean everything. A general truth as it sounds, the statement does not disclose the type of "replica" involved in the 
definition. That is, is it a replica of meaning (Linguistic, pragmatic, etc.)? Equivalence (semantic, stylistic, syntactic, functional)? Sense (general neutralized meaning)? Grammar? Style? Function? Intention? Or a combination of two or more of these?

Before attending fully to literary translation in specific details, a short purview of major definitions of translation in general can be introduced first.

\subsection{Defining Translation}

There has been a vicious circle, as it were, in the various and different definitions of the term "translation". The point of departure among them is what translation means first, as the underlined words in the following definitions indicate:

- "The process of translation between two written languages involves the translator changing an original written text....in the original verbal language (the SL) into a written text ... in a different verbal language (the TL)" (Munday, 2001, p. 5, in Rojo, 2009, p. 25).

- "Often, though not by any means always, [translation] is rendering the meaning of a text into another language in the way the author intended the text" (Newmark, 1988, p. 5).

- "Translation [is] the act or process of rendering what is expressed in one language or set of symbols by means of another language" (Encyclopedia Britannica. In Snell-Hornby, 1988, p. 39).

- "Translation [is] the replacement of textual material in one language (SL) by equivalent textual material in another language (TL)" (Catford, 1965, p. 20).

- "Translation is an expression in another language (or target language) of what has been expressed in another (source language), preserving semantic and stylistic equivalences" (Dubois, 1973, in Bell, 1991, p. 5).

- "Translation consists in reproducing in the receptor language the closest natural equivalent of the source language message, first in terms of meaning and secondly in terms of style" (Nida \& Taber, 1969, p. 12)

- "Translation is the replacement of a representation of a text in one language by a representation of an equivalent text in a second language" (Nida \& Taber, 1969, Hartmann \& Stork: 1972, in Bell, 1991, p. 7).

- "A good translation [is] that in which the merit of the original work is so completely transfused into another language..." (Tytler, in Bell, 1991, p. 11).

- "as a subject, translation refers to all the processes and methods used to render and/or transfer the meaning of the source language text into the target language..." (Ghazala, 2008/2012d, p. 1).

In one sense, all these definitions are either vague, loose or incomplete, to say the least. Starting with the left hand list of the table, "change" can involve the lack of commitment to the process of translating as a whole; whereas "render" (used in three definitions) is neutral, making no specification of what or how. "Replacement" (twice), on the other hand, might involve a kind of entire change. 
Table 1. Key Words in Translation Definitions

\begin{tabular}{ll}
\hline - change & - original text \\
- render & - meaning \\
- render & - what is expressed \\
- replacement (of) & - textual material \\
- expression & - what is expressed \\
- reproduction (of) & - equivalent meaning and \\
- replacement (of) & style \\
- transfuse & - representation \\
- render / transfer & - merit \\
& - meaning \\
\hline
\end{tabular}

"Expression" implies a TL-oriented expression of what is translated, while "reproduction" is SL-oriented production of what is translated. "Transfuse" in the sense of "penetrate" is vague in reference, which is different from "transfer" which implies among other things change, or transcription of SL words into TL letters (c.f. transference).

More confusing than the first list is the one on the right hand side of the table, which includes "what is translated". Obviously, except those that specify meaning and equivalent meaning of style, the rest avoids stating "what is translated" specifically on purpose. This is not quite helpful, for students and readers need elaboration of "what is translated" in clear terms. Therefore, the definitions that state it clearly as "meaning" are more reliable and comprehensible than otherwise. More significantly, "meaning" is what we usually render at translating from one language into another, be linguistic, denotative, functional, connotative, grammatical, lexical, semiotic, pragmatic, implicational, cultural, neutralized, stylistic, figurative and/or non-figurative.

I believe, whatever direction we take at defining translation, the key word of the definition is "meaning". Differences can occur about the type(s) of meaning intended owing to focus, text and context. The components of meaning are generally the components of language. Therefore, they are expected to be one and the same origin for live languages. The four major components of language (and hence meaning) are: Grammar, words, sounds and style (see Ghazala, 2008/2012, ch. 1 for further details).

In his updated cognitive-discoursal stylistic approach to the analysis and interpretation of literature, Simpson broadens the scope of the levels of language. For the purposes of this book, and as an extension to our discussion of meaning and its inherent links with language, it might be useful to reproduce the list of levels and equivalent branch of language study suggested by Simpson (2004, p. 5; See also Ghazala, 2011, p. 50). 
Table 2. Language Levels

\begin{tabular}{ll}
\hline Level of language & Branch of language study \\
\hline The sound of spoken language; the way & Phonology; phonetics \\
words are pronounced. & \\
The patterns or written language; the & Graphology \\
shape of language on the page. & \\
The way words are constructed; words & Morphology \\
and their constituent structures. & \\
The way words combine with other & Syntax; grammar \\
words to form phrases and sentences. & \\
The words we use; the vocabulary of & Lexical analysis; lexicology \\
language. & Semantics \\
The meaning of words and sentences. & \\
The way words and sentences are used & \\
in everyday situations; the meaning of & $\underline{\text { Pragmatics; discourse analysis }}$ \\
language in context. &
\end{tabular}

These basic levels of language are recently developed, identified interdisciplinary units and sources of meaning and interpretation in literary discourse. All these levels with no exception are what we work on in any analysis, or translation of literature inasmuch as they are relevant.

These intricacies of the concept of "meaning" in language and, hence, in translation lead to the heart of the book, literary translation.

\subsection{Literary Translation}

"Literary Translation" is a term used loosely to refer to the translation of literature. Perhaps "translating literature" or "the translation of literature" is more accurate than "literary translation" for the latter can be sometimes "unliterary" in the sense that the translation of an SL literary text may fail to be literary in the TL. That said, the term is used to be understood as a reference to the translation of literature that is hoped to be literary in the other language.

Some classic writers, poets and men of letters including Dryden, Saint Jerome, Humboldt Benjamin and others differing views about the possibility and the impossibility of translation (which is by implication literary translation) (see Schulte et al., 1992, for further details). Oddly enough, this controversy about a dichotomy of two extremes, the possibility and impossibility of literary translation is still going on these days. Strong voices like Humboldt in the $18^{\text {th }}$ and $19^{\text {th }}$ Centuries and the two pioneers of the Relative Theory of Language, Sapir and Whorf in the $20^{\text {th }}$ Century, were heard about the impossibility of translation, due to their acculturation of language. To them, language is 
culture-specific and an expression of culture. It is a part of culture with which it is impregnated. In this sense, the linguistic relativity has far-reaching implications for translation, rendering it impossible, especially literary translation which is imbued with culture (see also ibid., Boase-Beier, 2006; Rojo, 2009 for further argument).

This unfortunate line of argument has continued up today with scholars like Snell-Hornby, Bassnett-McGuire, Robinson and others who claim that language is a part of culture, not the other way round, i.e. culture is a small part of language represented by cultural terms and some special ways of expressing meaning in a language; the other greater part of language is "universal", i.e. non-cultural and common in all languages to all peoples the world over. These "universals", i.e. the vast majority of neutral words and expressions - are the integral part of language that makes translation possible. Snell-Hornby, to cite one example, calls "linguistic equivalence" and illusion, a chimera. She maintains that the concept of culture represents a totality of knowledge, proficiency and perception. Language is an integral part of culture, therefore, the translator needs to be not only bilingual, but also bicultural (1988, p. 42). This renders translation impossible, for biculturalness is impossible I believe. This approach to translation is outdated now due to the unstoppable continuation of the practice of translation and publication of great translations of great literary works by great translators worldwide (see also Ghazala, 2015 for further discussion).

Not only that, the unprecedented prosperous development of, and urgent need for translation as a discipline and practice is further confirmed evidence for yet a greater possibility of translation, whether Snell-Hornby and Company like it or not. She herself has minimized impossibility into difficulty of translating literary texts: "Literary texts, especially those embedded in a culture of the distant past, tend to be less easily translatable than those texts dealing with 'universals' of science". One still wonders about having a literary text which is not embedded with culture, past and present. Furthermore, this statement seems to be paradoxical with her claim of the totality of the culturalization of language as she concedes by implication that only some literary texts are embedded with culture, the rest are not, which is again not quite right for all literary texts are imbued with culture. Even Venuti, who criticizes the universal views of translation for ignoring cultural relativity, is himself admitting universalism about the nature and, hence, translation of literature (2000, p. 124. See Boase-Beier, 2006, p. 14).

Like describing the notorious statement, "translators are traitors" (Traduttori traditori) as a very old joke by Raffel (1988), it is sensible an approach to literary translation to stop describing it as impossible, even poetic texts, as Dryden and Jakobson claim, although the latter admits the possibility of what he calls a "creative transposition" of literature (see Schulte et al., 1992; Boase-Beier 2006, p. 13). A more practical approach is to declare that "the debate on the impossibility of translation seems pointless if we adopt a more flexible approach that shuns the belief in an extreme linguistic relativism. Another good reason to end this debate on the impossibility of translation is the undeniable importance of translators in society" (Rojo, 2009, p. 21). As she rightly says, and in an answer to those who question the possibility of translation, "why justify an almost four-thousand-year-old practice that 
continues to play a central role in modern society?". She adds, "how is translation going to be impossible if the shelves of bookstores and libraries are full of translations" (ibid., 26) (see also above). At best, and as Landers suggests, we may talk in terms of "the uniqueness of literary translation" being a creative process in the first place (2001, pp. 7-10).

Now, what is Literary Translation? Anani defines it crudely as "the translation of the different genres of literature including poetry narrative and drama. Like other types of non-literary translation, it involves transforming a verbal code into a different code, but unlike them, it is concerned not only in the referential meaning of words but also in their significance and effects" (1997, ch. 1). Landers defines literary translation in terms of uniqueness and creativity, describing it as "the most demanding type of translation". However he does not provide a straightforward definition for it throughout (2001). Most writers and translation theorists have not provided definitions for literary translation in clear terms. However, some classic writers define it through the literary translator's tasks and characteristics, what is translated (i.e. the spirit rather than the sense), the method of translation (i.e. free translation (or Dryden's "paraphrase"), not literal translation), or the function of the translation (that is, to educate readers in foreign literatures and cultures, increase the expressivity of meaning of one's own language, etc.) (see Schulte et al., 1992). Others, like Landers and Newmark, define literary translation in terms of problems and main characteristics of literary language. Newmark singles out five main features of literary language that have to be rendered by the translator: (1) figurativeness and allegory; (2) onomatopoeic nature (that sound is as important as meaning); (3) rhythm; (4) each word counts; and (5) full of polysemous words and collocations. (1998, pp. 102-103).

None of the previous definitions - or semi-definitions - can be satisfactory. A comprehensive definition in clear terms is required:

I define literary translation as a special type of translation that is concerned solely with translating literary genres and sub-genres into literary pieces of work in the TL, accounting for all features of literariness and creative style of the original, especially, re-registration, semantic density, syntactic and lexical intricacies, polysemy, Displaced interaction, multi-layeredness, symbolism / hypersemanticization, aestheticism, figurativeness and, most importantly, tone: the involvement of human feelings, sentiments and emotions.

The next point in order is at the heart of this paper, that is, "the literary translator".

\section{The Literary Translator}

Like any professional, the literary translator has to command certain capabilities and qualifications. I must insist that inasmuch as we do not have an ideal, or perfect translation, literary or other, there is no ideal or perfect translator, literary or other. Therefore, we have to come down to earth, be realistic and lower our expectations regarding the translator's potentials. Some of these potentials are shared by all types of translators; others are unique to literary translators only. The following list suggests a number of qualifications to be commanded by all types of translators in general including the literary translator, 
followed by another list especially for the latter's faculties and proficiencies.

(1) Due respect for the profession with a view to faithfulness and moral commitment to translating texts from one language into another. No deliberate additions, alterations, deletions or obliterations are exercised on the original unless justified on solid social, religious, cultural, moral, ideological or other grounds.

(2) Accuracy of rendering in the sense that everything in a text should be included or taken into account in translation, but not necessarily translated verbatim.

(3) Mastery of the two languages concerned in the translation, the SL and the TL, regarding the basics of their grammars (word order, major sentence and clause types, parsing, tenses, etc.), vocabularies (word combinations/collocations, technical terms of different fields and types, ,main figures of rhetoric, etc.), sound features (alliteration, assonance, consonance, rhyme, rhythm, and preferably a general idea about scansion, meter and foot).

(4) Competence in tone. Landers defines tone as "the overall feeling conveyed by an utterance, a passage, or an entire work, including both conscious and unconscious resonance" (2001, p. 69). That is why he regards it as one of the essential capabilities of the translator (ibid.: 8). Further, Anani assigns a whole chapter for "tone" in literary translation, defining it in terms of an attitude of irony, humor, seriousness, overstatement, understatement, etc. of the SLT author, which are prone to change from one age to another, and one language to another (1997, ch. 5).

(5) Good knowledge of the different types of style of both languages: grammatical, lexical and phonological features of style, in addition to the stylistic scales of formality (i.e. frozen formal 1 classical, formal/standard, informal, colloquial, slang, etc.). They can be sometimes essential to meaning in the various types of text.

(6) Good command of the differences between the conventions of the two languages involved, regarding the use, or non-use of formal/standard, old or modern, or colloquial, or mixed in both languages, or either language. In the case of English and Arabic, for example, while the conventions of English allow for a large use and borrowing from colloquial dialects, written Arabic conventions do not, and are still resistant to colloquialisms of all types. Written Arabic is standard only, but it is usually Modern Arabic described as MSA (Modern Standard Arabic), and occasionally old Arabic, or CA (Classical Arabic). Old English, on the other hand, has disappeared from today's formal/standard written dialect. It might be the case that, as Landers suggests, "the half-life of a translation...is from 30-40 years; every 30 years (or 40 or $50 \ldots$ ) the translation loses half its vitality, its freshness, to communicate to the reader in a contemporary voice" (2001, p. 10).

(7) Good knowledge of the SL culture, not necessarily to the same extent of the translator's knowledge of his/her native culture, for, unlike bilingualism, biculturalism is far-fetched.

(8) Good awareness of the world around us, and the knowledge shared by all humans about the latest changes and developments with respect to science and technology, cultures, social, political, religious, moral and ideological values and attitudes. 
(9) Due respect for the TL readership's religious, moral, social, cultural and ideological sensitivities and values. The translator is not an insensitive dolorous duck, but a sensitive human being who has feelings, values, sensitivities, biases, prejudices, attitudes and points of view.

(10) Specialism in translation (a higher degree), or at least a considerable proportion of background knowledge about translation theory (basic principles, guidelines, SL text, writer and translator's intentions, writer and translator's attitudes, SL and TL norms, problems and procedures/solutions) and, more importantly, the main translation methods (literal/semantic, free/communicative, pragmatic, non-pragmatic, creative, non-creative/ordinary, poetic/non-poetic, literary/ordinary, etc.): what, when and how.

(11) The translator's personal possession of the best and latest monolingual and bilingual dictionaries and references, alongside online facilities in this regard. One or two references never make a good translator.

In addition to these capabilities, the literary translator has yet further faculties to be equipped with:

(1) Creativity, or inventiveness.

(2) Special liking of literature, what Landers calls "sense of dedication" to literature. The literary translator should be first and foremost infatuated with literature.

(3) Psychological aptitude to live the TL literary translation with respect not only to events, characters and the plot, but also, and more importantly, to every word, syntactic structure and prominent sound feature. In short, the literary translator should have personal aptness to lend himself/herself wholeheartedly to construct a matching literary text in the TL through translation.

(4) Command of conventions of reading, understanding and interpreting literature.

(5) Good knowledge of literary genres and sub-genres in both languages.

(6) Considerable competence in figures of rhetoric (metaphors/allegory, similes, puns, metonyms, symbolism, irony, etc.) and special fixed phrases (e.g. idioms, proverbs, adages, etc.) in both languages.

(7) Awareness of the basics of sound/prosodic features in both languages, especially alliteration, rhyme, rhythm, meter, foot, beat, scansion and other essentials of prosody.

(8) Flexibility and open-mindedness.

(9) Background knowledge of some famous works of literature in both languages.

(10) Working with a back-of-the-neck idea that literature is symbolic, representing something else in human life.

(11) Humility. Why humility? A straightforward answer is put forward by Landers: "because even our best efforts will never succeed in capturing in all its grandeur the richness of the original" (2001, p. 8). Thus, I have a strong objection to those who propagate the so-called "inspired literary translator", implying that "inspiration is a precondition for translating literature", as Khulusi and some other writers claim (see Khulusi, 2000, pp. 18-22). This is unacceptable. There is no room to self-aggrandizement and monopolization of talents or good translations. I personally do not believe in an "inborn talented translator", or "inborn inspired translator", for there is an implication of arrogance 
and monopoly of literary translation by an alleged small group of self-acclaimed Godly (!) talented elite that should be discriminately self-opinionated as peerless, matchless, unsurpassed and the best in the field. Certainly not. I do believe in hard work and hard workers, thus, leaving the door wide open for any poor, "non-Godly talented" (!) and ordinary hard worker any time anywhere in the world, past, present and to come to become a masterly literary translator. This is the important sense of humility in translation. Those self-acclaimed talented and inspired translators ivory-tower themselves as distinguished, talented and unequaled, but they are not for sure.

(12) Perhaps most importantly, specialism, or vast knowledge of the crucial role of style in the understanding, interpretation and, hence, translation of literature. Indeed, and as Landers declares, in literary translation “... how one says something can be as important, sometimes more important, than what one says" (2001, p. 7). This takes us back to the first capability of creativity which is the product of style in the first place.

Now, we turn to the methods of translating literature. (See also Robinson 1997/2007; Anani, 1997, ch. 1, Dryden, Benjamin and others, in Schulte et al., 1992; Schogt, 1988; Ghazala, 2011 and others for more characteristics of the literary translator).

\section{Methods of Literary Translation}

The age-old two rival methods of translation, Free and Literal, still hold tight despite the many methods of translation suggested by translation theorists, writers and professional translators in the contemporary theory of translation. For the purposes of this work, there is no need to review these methods, but focus will be on the major methods of translation in circulation these days. (For a short review of a good number of translation methods going around, see Newmark, 1988, ch. 5).

\subsection{Semantic and Communicative Translation}

Among the celebrated pairs of polar methods of translation are Semantic and Communicative methods, suggested by Newmark (1981) in parallel with, and as a modern, but more specific alternative to the traditional pair, Literal and Free methods. He juxtaposes the two methods usefully and briefly. Chief among his distinction is that semantic translation is SLT-centered, whereas communicative translation is TLT reader-oriented, seeking to produce an equivalent effect on them. Well, right after this juxtaposition, Newmark makes a serious confession that "there is no one communicative nor one semantic method of translating a text...A translation can be more, or less semantic-more, or less, communicative - even a particular section or sentence can be treated more communicatively or less semantically"(ibid.: 40). This confession "upsets the applecart" as it were, confusing the two methods completely, for it is quite hard to imagine how the same sentence, which is at the end one idea, can be translated half semantically, half communicatively. Are these methods based on word-for-word translation so that some of the words of the sentence are translated semantically, others are translated communicatively? This is really difficult to accept in application.

Such objections can be understood by tracing Newmark's reconsideration of his methods in later books

Published by SCHOLINK INC. 
and statements of his. In his more famous book, A Textbook of Translation (1988), he relegates the two methods to a minor position, briefing them on passing in Chapter Five on "Translation Methods". This leads to the logical conclusion that had he been insistent on them, he would have reinstated and developed them in this and other later books of his. Still more surprising is his abandoning of the two or any other methods in favor of the importance of the language of the text. He says: "I unify my dual theory of semantic and communicative translation with three propositions ...". They are based on the importance of the language of the text; (1) the more important, the more closely translated; (2) the less important, the less closely related; and (3) the better written a text, the more closely translated whatever its degree of importance might be (1991, pp. 36-37). A further contradiction and confusion is caused by (3) which gives precedence to the good style of writing over importance. One is confused as to which to give priority at translating: importance, good writing, or communicative-semantic translation? The application of any of the three will invalidate the remaining two.

To bring the whole thing to the right track, it might be a good idea to do either of the following:

(a) either to decide on only one of the three factors pointed out above, and take it up as the criterion of the translation method recommended;

(b) or to go back to the old-age dichotomy of literal and free translation methods (and Newmark himself has done than in his book in 1988, assigning a large space for "Literal Translation"), the origin of semantic (i.e. more or less "literal") and communicative (i.e. roughly "free") translation. This will be strongly commended to put an end to confusion, especially with one or two modifications made on Newmark's points of juxtaposition between his two methods.

\subsection{Literal and Free Translation}

In a previous work of Ghazala, he suggests a kind of assimilation between major pairs of juxtaposed methods of translation, with the aim to bring them back to the general and well-known original (i.e. free and literal) and simplify the argument about translation methods especially for the students of translation and trainee translators (see Ghazala, 2008/2012, p. 4). Prior to suggesting a modified, more comprehensive and simplified version of translation methods matching that of Newmark's two methods pointed out above, a word is due about literal translation and free translation.

Literal Translation, to start with, is seriously mistaken as a reference to only one method of translation, the infamous word-for-word translation, concerned with translating individual words more out of context than in context. Although we translate words, "words alone do not carry meaning" (Raffel, 1994, p. 4). We translate words in context, and context is of different types: referential, collocational, syntactic, stylistic, semantic, pragmatic, situational, cultural, etc. (Newmark, 1988, p. 73 ). Translators deal more with ideas than words, and, in literary translation, they deal inter alia with cultures (Landers, 2001, p. 72).

Literal translation is normally taken to mean an accurate translation of meaning, no more no less, without beating about the bush. Everything is translated to a measure as much as possible: no deletions, no additions, no unnecessary exaggerations, no artificialities or groundless digressions. Thus, literal 
translation is "the accurate translation of meaning as closely, directly and completely as possible" (see also Ghazala, 2008/2012, p. 9). This is also the sense meant by Newmark in his discussion of the term. He describes himself as "literalist", that is, a partisan of literalness of meaning, not words. In the Preface, he declares: "I am somewhat of a "literalist", because I am for truth and accuracy...words as well as sentences and texts have meaning, ...you only deviate from literal translation when there are good semantic and pragmatic reasons for doing so..." (1988: xi \& 73). Therefore, the literal translation of meaning is after sense in the first place, as accurately as possible, be it figurative, non-figurative, denotative, connotative, cultural, non-cultural or other. Here are examples:

(1) The wind of change has blown هبت رياح التعيير

هبت ريح عاصف على شمالي البلاد A strong wind is blew North of the Country

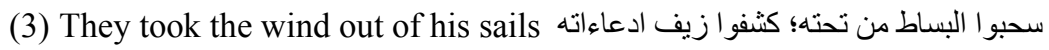

ذهبت أماني مع الريح / أدر اج الرياح دونهاء

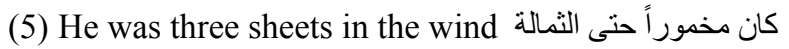

من يزرع الثوك لا يجني العنب. Those who sow the wind reap the whirlwind

خدت الريح (7) The wind went down

كان كلامها فقاعات في الهواء (8) Her talk was all wind

(9) The sick man broke wind أخرج المريض رئاء

(10) You go against the wind! إنك تسير عكس التيار

All these are literal translations of the sense of the original as accurately, closely and completely as possible, be it metaphorical or not. None of the English statements has lost any part of its original sense in the Arabic translation. Whether this sense is figurative or not in both languages is next to achieving accuracy in translation.

Free Translation, on the other hand, is again misunderstood to be a method that allows the translator to add, delete, drop, shorten, expand, adapt or change meaning or any part of meaning. Another possibility of misunderstanding free translation is that it is concerned with the message which is reshaped and reconstructed in the translator's own way. In other words, freedom of translation is freedom of language and style, not freedom of rendering the message. There is no play with the message, but a play with wording it. In other words, the translator is free to change the style, but not free to change the message. And here lies the big mistake, the mistake that a difference of the style of expression does not affect the message.

A third mistaken common practice of free translation is the tendency on the part of some translators to over-exaggerate, overemphasize, be over-expressive, classical/frozen formal, or rhetorical with the aim to provoke greater effect and be more impressive. This is due to their misapprehension of good translation to be as much effective, rhetorical, expressive and impressive as possible, regardless of the types of text, context, readership, topic, historical background and register.

To overcome any shade of misunderstanding, I would define free translation as "a method concerned more with the message that the fine details of meaning and its componential constituent words in 
context. Its focal point is the production of (a stylistic-semantic) effect of some kind on the TL readers to impress them more unjustifiably than justifiably by means of exaggeration, provocation, prejudice, rhetoric, expressiveness, classical/frozen formality, understatement, overstatement, aesthetic, pragmatic, religious, cultural, social, ideological or other factors". These are features of style and tone before anything else.

Free translation is two types (see also Ghazala, 2008/2012d, ch. 1):

(a) Bound Free Translation: a little free translation that might somehow exaggerate, undermine, etc. more than the original without going far away from its lexical/referential meaning, with the aim of making effect or impression of some kind: e.g.

- We feel sorry about the situation نأسف أنثد الأسف / نعض أصابع الندم لما آل إليه الوضع (over-exaggeration about regret) (cf. نأسف للوضع)

- Parsimony is not advisable التقتير شر مستطير (a collocation more rhetorical, emphatic and effective than normal (cf. التقتير غير محمود)

- You are quite right. الحق أبلج والباطل لجلج ( a proverb: rhetoric and metaphorical) (cf. أنت محق / على حق). (b) Loose Free Translation: a greater space of freedom is exercised here by the translator who may go beyond the referential meaning to explore the inferential meaning, which is in other words a pragmatic meaning, allegedly tracing the authorial intentions. Here are illustrative examples:

(The Assad regime of Syria representative to the UN said: "We will kill the Syrian People" (cf. The Syrian People is our responsibility).

لاى الجيش السوري قدرات (وزير خارجية نظام الأسد) - (the Assad regime of Syria foreign minister said "The Syrian army has special potentials of humiliating the Syrians") (cf. The Syrian army has special military potentials).

- He keeps a low profile يكاد المريب يقول خذوني (cf. يتوارى عن الأنظار)

Although these cannot be described as common in all types of translation, we have to admit that no one denies their recurrence in the translation of literature particular. Both types of free translation method are widely applied due to their relevance to (a) style, tone and rhetoric, and (b) pragmatic implications. At this stage, we come closer to the translation method appropriate for translating literature. Before that, it is high time to introduce an alternative table with a view to combining, outlining, simplifying and merging the major methods of translation discussed earlier and their characteristic features juxtaposed. 
Table 3. Translation Methods Juxtaposed

\begin{tabular}{cc}
\hline Free/Communicative Trans. Method & Literal/Semantic Trans. Method \\
\hline priority to message & priority to meaning \\
priority to effect & priority to accuracy \\
faithful to TL norms and culture & faithful to SL norms and culture \\
faithful to TL readership & Faithful to SL readership \\
tends to translate expressive, pragmatic & insists on referential / lexical / surface \\
meaning and intentions & meaning \\
creative & non-creative \\
pragmatic & non-pragmatic \\
more literary & less literary \\
special concern with TL style\& tone & normal concern with SL style \& tone \\
committed to TL translation & committed to SL text \\
attempts to render the spirit & attempts to render sense \\
\hline
\end{tabular}

\section{Creative Literary Stylistic Translation}

In a previous work of his, Cognitive Stylistics and the Translator (2011), the author of this book undertakes and develops a style-based Method of Direct Translation, put forward by Gutt (2000). It attempts to preserve not just what the source text said, but also how it said it. It pursues all nuances of style and stylistic choices. The translator is concerned more with what goes in the people's mind beyond the actual words on the page than what they referentially mean in context in literary texts. Hence, the method is appropriate for literary translation, where faithfulness is both to content as much as to style. This is clearly a cognitive stylistic translation practice. In this sense, direct translation is an interpretive activity which retains what features of style might mean at the overall context of the literary text, not only their formal shape. Therefore, Gutt declares that direct translation is more difficult for the reader to process, yet it is rewarding for it provides more cognitive and emotional effects (ibid.). (See also Boase-Beier, 2006; Ghazala, 2011, ch. 4).

In an extension to this direct translation method in relation to literary translation in particular, and to avoid any confusion with other direct methods of translation, a method of creative translation is proposed here. As argued above, the clue to literary language is the set of the features of literariness that make literature into literature.

Therefore, the translation of literature is expected to attend to these features entirely. And if any translation of literature is meant to be constructed as a literary translation, that is, a piece of literature in the TL, it has to trace the features of literariness in the SLT to construct them in the TLT. And since the features of literariness are features of the style of literary language, since style is the source of creativity in literary translation, and since style is the master key, as it were, to understanding, 
interpreting and, hence, translating literature, the more appropriate method to the translation of literature can be based on literary style which is defined and constructed in terms of features of literariness singled out in 4 above. Hence the suggestion of the literary style-based method of translation, "creative literary stylistic translation". The main features that characterize creative literary stylistic translation are: creativity, figurativeness, lexical and syntactic elaboration expressivity, rhetoric, impressiveness, effectiveness, aesthetics, inventiveness, pragmaticality, tone, resonance, emotionality, human feelings, (frozen/classical) formality, flexibility, humility and captivation (of TL readers).

I hasten to point out that any of the major translation methods outlined above (especially, semantic, communicative, literal free and pragmatic) can be sometimes creative in style, meeting some of the criteria of this method just outlined. Therefore, they are occasionally employed and implied in the suggested method of translating literature, creative literary stylistic translation.

\section{Conclusion}

This paper has provided initial definitions and details necessary for the students and readers of literary translation to be aware of before embarking on more specific arguments and applications. Different definitions of literature are provided. Then the polarization between literary language and non-literary language in terms of style is recognized, but was found inevitable and useful to literary translators for they translate literarily in terms of the features which make literature into literature, that is, features of literariness in literature like: semantic density, lexical and syntactic elaboration, medium dependence, re-registration, polysemy, the possibility of reading literature at more than one level, the involvement of human feelings, etc. It has been argued that the pivotal importance of these features is immeasurable to literary translators.

The third major point raised has been literary translation which has been defined in as a special type of translation that accounts for all features of literariness and style of the original, especially those pointed out above. Then the special capabilities and characteristics of the literary translator are discussed. They have been meant to demonstrate the tall order of becoming a literary translator.

The penultimate point raised has tackled the major methods of translation in the field. The final point, and, eventually, the ultimate objective aimed at by this paper has been the suggestion of a literary style-based method of translation for translating literature: "a creative literary stylistic translation method". It has been claimed that this method can respond to the demanding requirement of translating literature by singling out creativity and its source, style, to represent the core of the literariness of literature. It is hoped that this method would be a new springboard for a more creative, truthful, scrupulous and impressive translation that may meet the necessary requirements for a good literary translation of literature now. 


\section{References}

Anani, M. (1997). Literary Translation (in Arabic). Libraire du Liban: Lebanon.

Baker, K. (1980). I Have no Gun But I Can Spit: An Anthology of Satirical and Abusive Verse. London: Eyre Methuen.

Bell, R. (1991). Translation and Translating. London and New York: Longman.

Boase-Beier, J. (2006). Stylistic Approaches to Translation. Manchester, UK \& Kinderhook, USA: St. Jerome Publishing.

Brumfit, C., \& Carter, A. (Eds.). (1986). Literature and Language Teaching. OUP.

Carter, R. A. (1979). Towards a Theory of Discourse Stylistics: A Study of Some Applications of Linguistic Theory to the Analysis of poetry with Particular Reference to W. H. Auden (Unpublished PH. D. Thesis). University of Birmingham.

Carter, R., \& Simpson, P. (Eds.). (1989). Language, Discourse and Literature: An Introductory Reader in Discourse Stylistics. London: Unwin Hyman.

Carter, A., \& Nash, W. (1983). Language and literariness. Prose Studies, 62, 123-141.

Carter, A., \& Nash, W. (1990). Seeing Through Language: A Guide to Styles of English Writing. Basil Blackwell.

Catford, J. (1965). A Linguistic Theory of Translation. London: OUP.

Chapman, R. (rev.). (1977). Roget's International Thesaurus (4th ed.). New York: Harper \& Row Inc. Collins York English Dictionary (Millennium ed.). (2000). Collins \& Library of Lebanon.

Collins, H. (2002). Collins Thesaurus: The Ultimate Wordfinder (New ed. 2003). Collins.

Dryden, J. (1992). On translation. In R. Schulte, \& J. Biguenet (Eds.), Theories of Translation: An Anthology of Essays From Dryden to Derrida. Chicago and London: The University of Chicago Press.

Eagleton, T. (1983). Literary Theory: An Introduction. Basil Blackwell.

Enkvist, N. (1973). Linguistic Stylistics. Paris: Mouton The Hague.

Fish, S. (1980). Is There a Text in This Class? The Authority of Interpretive Communities. Harvard UP.

Fowler, R. (1981). Literature as Social Discourse: The Practice of Linguistic Criticism. London: Batsford.

Fowler, R. (1998/1996). Linguistic Criticism. Oxford: Oxford University Press.

Ghazala, H. (1987). Literary Stylistics: Pedagogical Perspectives in an EFL Context. Thesis: University of Nottingham, UK.

Ghazala, H. (2008/2012). Translation as Problems and Solutions: A Textbook for University Students and Trainee Translators. Beirut: Dar El-Ilm Lil-Malayin.

Ghazala, H. (2011). Cognitive Stylistics and the Translator. London: Sayyab Books.

Ghazala, H. (2012). Translating the Media and Political Idiom: A Textbook for University Students. Jeddah: Konooz Al-Marifa.

Ghazala, H. (2015). Translating Culture: A Textbook. Jeddah: Konooz Al-Marifa.

Published by SCHOLINK INC. 
Gutt, E. (2000). Translation and Relevance (2nd ed.). Manchester: St. Jerome.

Herman, V. (1996). Dramatic Discourse: Dialogue as Interaction in Plays. London: Routledge.

Jeffries, L., \& McIntyre, D. (2010). Stylistics. Cambridge: Cambridge University Press.

Khulusi, S. (2000). The Art of Translation (in Arabic) (2nd ed.). Cairo: Al-Haiah Al-Misriyyah LilKitab.

Landers, C. (2001). Literary Translation: A Practical Guide. Clevedon: Multilingual Matters.

Leech, C., \& Short, M. (1981). Style in Fiction: A Linguistic to English Fictional Prose. London and New York: Longman.

Nash, W. (1985). The Language of Humour: Style and Technique in Comic Discourse. London and New York: Longman.

Newmark, P. (1981). Approaches to Translation. Oxford: Pergamon Press.

Newmark, P. (1988/1995). A Textbook of Translation. London : Prentice Hall.

Newmark, P. (1991). About Translation Clevedon. Philadelphia, Adelaide: Multilingual Matters Ltd.

Newmark, P. (1998). More Paragraphs on Translation. Philadelphia, Adelaide: Multilingual Matters Ltd.

Nida, E., \& Taber, C. (1969). The Theory and Practice of Translation. United Bible Society.

Robinson, D. (1997/2007). Becoming a Translator. London and New York: Routledge.

Rojo, A. (2009). Step by Step: A Course in Contrastive Linguistics and Translation. Peter Lang.

Raffel, B. (1988). The Art of Translating Poetry. Pennsylvania: The Pennsylvania State University Press.

Raffel, B. (1994). The Art of Translating Prose. Pennsylvania: The Pennsylvania State University Press.

Schogt, G. (1988). Linguistics, Literary Analysis, and Literary Translation. Toronto \& London: University of Toronto Press.

Schulte, R., \& Biguenet, J. (1992). Theories of Translation: an Anthology of Essays From Dryden to Derrida. Chicago and London: The University of Chicago Press.

Simpson, P. (2004). Stylistics: A Resource Book for Students. London \& New York: Routledge.

Snell-Hornby, M. (1988/1995). Translation Studies: An Integrated Approach. Amsterdam/Philadeliphia: John Benjamins Publishing Company.

Venuti, L. (ed.). (2000/2004). The Translation Studies Reader. London and New York: Routledge.

Wales, K. (1989/2001). A Dictionary, of Stylistics. Longman.

Wellek, R. (1982). The Attack on Literature and Other Essays. Brighton: The Harvester Press.

Widdowson, H. (1975). Stylistics and the Teaching of Literature. London: Longman.

Williams, R. (1976/1983). Keywords: A Vocabulary of Culture and Society. Fontana. 